\title{
Гемофагоцитарный лимфогистиоцитоз
} в педиатрической практике

\author{
Н.Г. Багдасарян ${ }^{1}$, Г.С. Айвазян ${ }^{1}$, Л.А. Аветисян ${ }^{2,3}$, Н.Р. Мнацаканян ${ }^{3}$, Л.Т. Алексанян ${ }^{3}$ \\ ${ }^{1}$ Медицинский центр «Святой Григорий Просветитель»; Республика Армения, г. Ереван \\ ${ }^{2}$ Министерство здравоохранения Республики Армения; Республика Армения, г. Ереван \\ ${ }^{3}$ Ереванский государственный медицинский университет имени Мхитара Гераци; Республика Армения, г. Ереван
}

PEЗЮME

\begin{abstract}
Цель статьи: представить клинический случай успешной диагностики и лечения гемофагоцитарного лимфогистиоцитоза (ГЛГ) у девочки 2,5 года, госпитализированной по поводу тяжелой пневмонии.

Основные положения. ГЛГ представляет собой синдром, клинически проявляющийся системной воспалительной реакцией организма, подобной септическому процессу, в большинстве случаев он с трудом диагностируется врачами-педиатрами. Диагностическую значимость имеют развивающиеся панцитопения и гиперферритинемия. Мы представляем клинический случай девочки в возрасте 2,5 года, госпитализированной по поводу тяжелой пневмонии с развившимся ГЛГ. Поскольку нет единого подхода к лечению вторичного ГЛГ, был проведен консилиум и решено начать лечение со стероидной терапии (дексаметазона) и внутривенного введения иммуноглобулина (Октагама), а при отсутствии эффекта в течение первой недели подключить цитостатики. Лечение начато сразу после обнаружения в мазке костного мозга активных макрофагов. Уже на пятые сутки терапии отмечалась положительная клиническая и параклиническая динамика, в связи с чем принято решение воздержаться от агрессивной иммуносупрессии. Практически через месяц при отсутствии признаков дисфункции органов и нормализации показателей ребенок был выписан из стационара.

Заключение. При ГЛГ имеется высокий риск летального исхода, поэтому очень важны ранняя диагностика и своевременно начатая терапия. Особенность данного случая заключается в том, что нам удалось быстро поставить диагноз, рано начать лечение и получить полную ремиссию без агрессивной иммуносупресии.

Ключевые слова: гемофагоцитарный лимфогистиоцитоз, макрофаги, панцитопения.
\end{abstract}

Вклад авторов: Багдасарян Н.Г. - план обследования и лечения пациентки, интерпретация лабораторных данных, окончательное оформление статьи, утверждение рукописи в печать; Айвазян Г.С. - интерпретация клинических и лабораторных данных и оформление статьи; Аветисян Л.А. - лечение пациентки, обработка анкетных данных; Мнацаканян Н.Р., Алексанян Л.Т. — обзор публикаций по теме статьи.

Конфликт интересов: авторы заявляют об отсутствии возможных конфликтов интересов.

Для цитирования: Багдасарян Н.Г., Айвазян Г.С., Аветисян Л.А., Мнацаканян Н.Р., Алексанян Л.Т. Гемофагоцитарный лимфогистиоцитоз В педиатрической практике. Доктор.Ру. 2021; 20(3): 66-69. DOI: 10.31550/1727-2378-2021-20-3-66-69

\section{Hemophagocytic Lymphohistiocytosis in Children}

\author{
N.G. Bagdasaryan ${ }^{1}$, G.S. Ayvazyan ${ }^{1}$, L.A. Avetisyan ${ }^{2,}{ }^{3}$, N.R. Mnatsakanyan ${ }^{3}$, L.T. Aleksanyan ${ }^{3}$ \\ ${ }^{1}$ St. Gregory the Illuminator Medical Centre; 10 Gyurdzyan Str., Yerevan, Republic of Armenia 0056 \\ ${ }^{2}$ Ministry of Health of the Republic of Armenia; 3 Government House, The Republic Square, Yerevan, Republic of Armenia 0056 \\ ${ }_{3}^{3}$ Yerevan State Medical University; 2 Koryun Str., Yerevan, Republic of Armenia 0025
}

\section{ABSTRACT}

Objective of the Paper: To present a clinical case of a 2.5-year girl hospitalised with severe pneumonia with associated hemophagocytic lymphohistiocytosis (HLH).

Key Points. HLH is a syndrome, the clinical representation of which is a system sepsis-like inflammatory reaction; in the majority of cases, this condition is hardly diagnosed by paediatricians. Associated pancytopenia and hyperferritinaemia are of diagnostic importance. Here we present a clinical case of a 2.5-year girl who was hospitalised with severe pneumonia and associated HLH. As there is no common approach to the management of $\mathrm{HLH}$, we summoned a board of doctors and decided to start steroid therapy (dexamethasone) and IV immunoglobulin (0ctagam), and if there was no effect from therapy within a week, cytostatic agents would be added. The therapy was initiated promptly after macrophages had been found in bone marrow smear. Clinical and paraclinic improvements were noted on day 5, so aggressive immunosuppresion was not initiated. In a month there were no signs of organ dysfunction; the values normalised, and the child was discharged from the inpatient clinic.

Багдасарян Нуне Геворговна - Ә. м. н., профессор, руководитель педиатрической клиники медицинского центра «Святой Григорий Просветитель». 0056, Республика Армения, г. Ереван, ул. Гюрджяна, д. 10. E-mail: nun_bag@таil.ru

Айвазян Гоар Сергеевна (автор для переписки) - к. м. н., доцент, врач педиатрической клиники медицинского центра «Святой Григорий Просветитель».0056, Республика Армения, г.Ереван, ул. ююрджяна, д.10. E-mail: ayvgohar@gmail.com

Аветисян Лилит Артаваздовна - начальник Департамента здоровья детей Министерства здравоохранения Республики Армения, ассистент кафедры педиатрии № 1 ЕрГмУ им. М. Гераци. 0025, Республика Армения, г. Ереван, ул. Корюна, д. 2. E-mail: md.lilitavetisyan@gmail.com Мнацаканян Нанэ Рудольфовна - к. м. Н., ассистент кафедры педиатрии № 1 ЕрГму им. М. Гераци. 0025, Республика Армения, г. Ереван, ул. Корюна, д. 2. E-mail: nanemnatsakanyan@gmail.com

Алексанян Лилит Тадевосовна - ассистент кафедры педиатрии № 1 Ергму им. М. Гераци. 0025, Республика Армения, г. Ереван, ул. Корюна, d.2.E-mail: lilit.aleksanyan.87@mail.ru 
Conclusion. HLH is associated with high mortality, therefore, early diagnosis and therapy are critical. The specificity of this case is that we managed to promptly diagnose the condition, initiated treatment and achieved complete remission without aggressive immunosuppresion. Keywords: hemophagocytic lymphohistiocytosis, macrophages, pancytopenia.

Contributions: Bagdasaryan, N.G. - patient examination and management plan, laboratory data interpretation, article finalisation, approval of the manuscript for publication; Ayvazyan, G.S. - clinical and laboratory data interpretation; Avetisyan, L.A. - therapy, personal data processing; Mnatsakanyan, N.R. and Aleksanyan, L.T. — thematic publications reviewing.

Conflict of interest: The authors declare that they do not have any conflict of interests.

For citation: Bagdasaryan N.G., Ayvazyan G.S., Avetisyan L.A., Mnatsakanyan N.R., Aleksanyan L.T. Hemophagocytic Lymphohistiocytosis in Children. Doctor.Ru. 2021; 20(3): 66-69. (in Russian). D0I: 10.31550/1727-2378-2021-20-3-66-69

\section{ВВЕДЕНИЕ}

Гемофагоцитарный лимфогистиоцитоз (ГЛГ) характеризует ряд заболеваний врожденного и приобретенного генеза, в основе которых лежит нарушение регуляции иммунного ответа с последующей выработкой цитотоксических Т-лимфоцитов [1]. Как следствие, развивается системная воспалительная реакция с активацией и пролиферацией Т-лимфоцитов и макрофагов, фагоцитозом эритроцитов, лейкоцитов, тромбоцитов и их клеток-предшественников, с мультиорганной дисфункцией $[1,2]$, очень похожей на тяжелый сепсис, что затрудняет его диагностику [3].

ГЛГ может осложнить течение основного заболевания и в случае отсутствия своевременного лечения привести к смертельному исходу $[4,5]$. Различают первичный и вторичный ГЛГ [6-8]. Первичный ГЛГ - это результат мутации генов, кодирующих белки, играющих важную роль в регулировании цитотоксических лимфоцитов [7]. Способствовать развитию вторичного ГЛГ могут вирусы (герпесвирусы, парвовирус В19, аденовирус, энтеровирусы, вирусы Коксаки, вирус гриппа А H5N1), ГЛГ может также возникнуть при туберкулезе, брюшном тифе, болезни Лайма, бруцеллезе, пневмонии, риккетсиозе, паразитарных и грибковых инфекциях, злокачественных новообразованиях и аутоиммунных заболеваниях $[3,8,9]$.

Мы представляем клинический случай с целью акцентировать внимание педиатров на нередком, однако часто не диагностируемом синдроме и показать возможность его терапии без использования агрессивной иммуносупрессии.

\section{КЛИНИЧЕСКОЕ НАБЛЮДЕНИЕ}

В педиатрическую клинику Университетского больничного комплекса «Мурацан» г. Еревана в мае 2018 года на 5-й день заболевания поступила девочка в возрасте 2 лет 6 месяцев с жалобами на лихорадку, общую слабость, кашель.

Анамнез жизни ребенка без особенностей: родилась доношенной, показатели роста и развития в пределах нормы, профилактические прививки получила по национальному календарю.

Данная госпитализация - третья. Предыдущие две госпитализации были по поводу пневмонии (диагнозы поставле- ны по критериям В03 и подтверждены рентгенологически). При этом состояние ребенка оценивали как умеренно тяжелое без выраженных клинико-гематологических особенностей.

После второй госпитализации девочку с улучшением выписали с продолжением курса антибиотикотерапии (аминопенициллина) в домашних условиях, а через 6 дней она снова поступила в больницу (все три госпитализации в течение 5 месяцев).

На момент поступления состояние ребенка тяжелое, температура $-40^{\circ} \mathrm{C}$, резкая слабость, признаки дыхательной недостаточности (ДН): одышка (ЧДД - 50 в мин), ЧСС 140 в мин, сатурация $\mathrm{SpO}_{2}-92 \%$, втяжения нижних отделов грудной клетки; локальная физикальная симптоматика справа. Рентгенологически вновь подтвердилась пневмония - наддиафрагмальный инфильтрат справа. Был поставлен диагноз пневмонии, и началась антибиотикотерапия с резервного препарата моксифлоксацина (с учетом предыдущего анамнеза).

В общем анализе крови в день поступления в клинику уровень гемоглобина - 118 г/л, СРБ -48 мг/л, эритроциты - 4,7 × 1012/л, тромбоциты - $1491 \times 10^{9} /$ л, лейкоциты $6,1 \times 10^{9}$. На третий день госпитализации и антибиотикотерапии при отсутствии положительной динамики (сохранялись температура до $38,3^{\circ} \mathrm{C}$, слабость, усугубились признаки ДН (ЧДД - 54 в мин, ЧСС - 164 в мин, $\mathrm{SpO}_{2}-86 \%$ ), на повторной рентгенограмме - картина двусторонней базальной полисегментарной пневмонии справа с реакцией плевры с обеих сторон) больную перевели в отделение интенсивной терапии. У девочки отмечалась гепатоспленомегалия.

В этот же день в связи с ухудшением состояния больной повторно проведен общий анализ крови, в котором выявилась панцитопения, усугубившаяся в последующие дни.

Наглядно изменения показателей периферической крови пациентки представлены в таблице 1, динамика биохимических показателей - в таблице 2.

Отмечались повышение уровня СРБ до 96 мг/л, высокие показатели амилазы (547,2 Ед/л) и липазы (733 Ед/л), диастазы в моче (6071,7 Ед/л), триглицеридов (2,1 ммоль/л). По данным коагулограммы, гипофибриногенемия не выявлена.

Аинамика показателей общего анамиза крови пациентки в отАелении интенсивной терапии

Dynamics of the patient's clinical blood analysis in A\&E Unit

\begin{tabular}{|l|l|l|l|l|}
\hline \multicolumn{1}{|c|}{ Показатели / Parameter } & \multicolumn{1}{c|}{ 11 мая / 11th May } & \multicolumn{1}{c|}{ 12 мая / 12th May } & 13 мая / 13th May & 21 мaя / 21st May \\
\hline Гемоглобин, г/л / Hemoglobin, g/L & 102 & 91 & 82 & 102 \\
\hline Эритроциты, $\times 10^{12} /$ л / RBC, $\times 10^{12} / \mathrm{L}$ & 3,7 & 3,8 & 3,3 & 3,9 \\
\hline Тромбоциты, $\times 10^{9} /$ л / Platelets, $\times 10^{9} / \mathrm{L}$ & 74,0 & 52,0 & 50,0 & 580,0 \\
\hline Лейкоциты, $\times 10^{9} /$ л / WBC, $\times 10^{9} / \mathrm{L}$ & 2,5 & 1,7 & 1,5 & 11,0 \\
\hline
\end{tabular}


Аинамика показатемей биохимического анамиза крови пациентки в отАелении интенсивной терапии

Dynamics of the patient's biochemical blood assay in A\&E Unit

\begin{tabular}{|c|c|c|c|c|c|}
\hline Показатели / Parameter & $\begin{array}{l}11 \text { мая / } \\
11 \text { th May }\end{array}$ & $\begin{array}{l}12 \text { мая* / } \\
12 \text { th May* }\end{array}$ & $\begin{array}{l}14 \text { мая / } \\
14 \text { th May }\end{array}$ & $\begin{array}{l}16 \text { мая** / } \\
16 \text { th May** }\end{array}$ & $\begin{array}{l}21 \text { мая / } \\
\text { 21st May }\end{array}$ \\
\hline Общий белок, г/л / Total protein, g/L & 37,2 & 37,9 & 54,3 & 74,9 & 70,7 \\
\hline $\begin{array}{l}\text { Аланинаминотрансфераза, Ед/л / } \\
\text { ALT, U/L }\end{array}$ & 40,8 & 130,4 & 72,4 & 105,9 & 67,0 \\
\hline $\begin{array}{l}\text { Аспартатаминотрансфераза, Ед/л / } \\
\text { AST, U/L }\end{array}$ & 169,9 & 560,3 & 263,5 & 222,0 & 30,4 \\
\hline 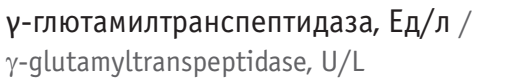 & - & - & 249,9 & 262,1 & 200,6 \\
\hline Феритин, нг/мл / Ferritin, ng/mL & - & - & $>2000$ & - & 251,4 \\
\hline Лактатдегидрогеназа, Ед/л / LDH, U/L & - & 1199 & 1866 & 1481 & 405 \\
\hline
\end{tabular}

На сонографии органов брюшной полости - гепатомегалия, увеличение головки и хвостового отдела панкреаса, спленомегалия, наличие свободной жидкости в брюшной полости. По данным ЭхоКГ, в полости перикарда - небольшое количество жидкости в передней камере. На КТ легких - картина полисегментарной пневмонии, наличие внутрилегочных лимфопролиферативных утолщений.

С целью выявления всех возможных причин панцитопении были проведены консультации гематолога, инфекциониста, фтизиатра. Исключены лейшманиоз (метод быстрой иммунохроматографии, гК39 тест), ВИЧ (сывороточный тест), вирусные гепатиты В и С. Методом ИФА обнаружены антитела класса IgM к капсидному антигену вируса Эпштейна Барр (EBV VCA-IgM). В результате исследования найден также парвовирус B19 (B19V).

В связи с отсутствием эффекта моксифлоксацин был заменен на меропенем тригидрат, проводились инфузионная терапия, переливания плазмы и эритроцитарной массы. Так как в условиях угнетения костного мозга высок риск развития пневмоцистоза, в схему лечения добавили ко-тримоксазол.

С учетом наличия у ребенка мультиорганной дисфункции, отсутствия клинического улучшения, усугубляющейся панцитопении и выраженных измененных биохимических показателей крови проведено исследование костного мозга, выявившее гипоклеточный костный мозг с единичными мегакариоцитами, раздражение моноцитарного ростка кроветворения с визуализацией промоноцитов и монобластов, повышенное количество макрофагальных клеток (7\%), сужение красного ростка кроветворения.

По морфологическим данным больной выставлен диагноз ГЛГ, который подтвержден в клинике педиатрической онкологии, гематологии и клинической иммунологии г. Дюссельдорфа (рис.).

\section{ОБСУЖДЕНИЕ}

Согласно Федеральным клиническим рекомендациям [1], диагностика ГЛГ основывается на наличии 5 из 8 диагностических признаков (лихорадка, спленомегалия, панцитопения, гипертриглицеридемия или гипофибриногенемия, гемофагоцитоз в мазке костного мозга, лимфатических узлах или
Рис. Процесс гемофагоцитоза в мазке костного мозга больной

Fig. Hemophagocytosis in patient's bone marrow smear

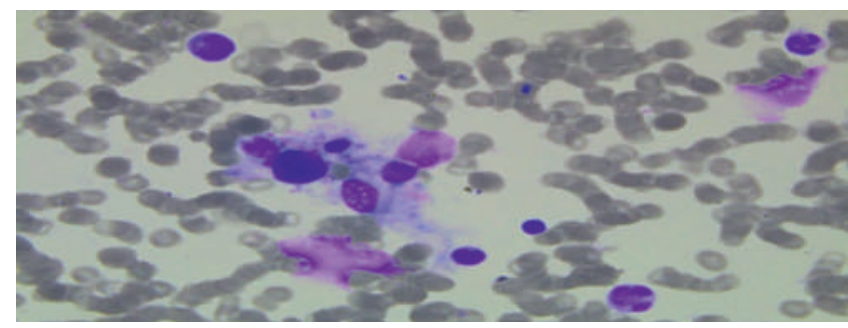

ликворе, низкая или отсутствующая активность естественных киллерных клеток, гиперферритинемия (> 500 мкг/л), увеличение уровня растворимого CD25 в сыворотке > 2500 Ед/л). Для диагностики первичного ГЛГ в дополнение к определению диагностических критериев проводится молекулярно-генетическое исследование.

В случае нашей больной диагноз ГЛГ был поставлен на основании наличия у нее лихорадки, спленомегалии, гиперферритинемии (уровень ферритина > 2000 нг/мл), панцитопении и гемофагоцитоза в мазке костного мозга. По балльной шкале точность диагностики гемофагоцитарного синдрома в случае нашей больной составила 98\% [10].

В описываемом случае диагноз ГЛГ рассматривался нами как вторичный по отношению к тяжелой пневмонии с мультиорганной дисфункцией.

Наши данные совпадают с данными литературы [3, 4, 7, 8], где указывается, что наиболее часто ГЛГ ассоциируется с вирусными инфекциями. При этом более 50\% составляет герпесвирусная инфекция: как первичная, так и реактивация вирусом Эпштейна - Барр (у больной выявлены вирус Эпштейна - Барр и парвовирус В19).

Согласно Федеральным клиническим рекомендациям и HLH-2004 протоколу, лечение ГЛГ основано на назначении кортикостероидной терапии в сочетании с этопозидом и циклоспорином А (при ее эффективности длительность назначения составляет 8 недель) [1, 11], при отсутствия эффекта показано проведение химиотерапии 
или трансплантации костного мозга [9]. В случае вторичного ГЛГ, ассоциированного с вирусной инфекцией или с онкологией, терапия синдрома может быть начата с лечения причины, приведшей к активации иммунной системы, и лишь при необходимости подключается хемоиммунотерапия [1, 11].

Поскольку нет единого подхода к лечению вторичного ГЛГ, был проведен консилиум и решено начать лечение со стероидной терапии (дексаметазона) и внутривенного введения иммуноглобулина, а при отсутствии эффекта в течение первой недели подключить цитостатики. Лечение начато сразу после обнаружения в мазке костного мозга активных макрофагов.

Уже на 5-е сутки терапии отмечалась положительная клиническая и параклиническая динамика, в связи с чем принято решение воздержаться от агрессивной иммуносупрессии.

\section{ЛИТЕРATУPA / REFERENCES}

1. Румянцев А.Г., Масчан А.А., Масчан М.А. и др. Федеральные клинические рекомендации по диагностике и лечению гемофагоцитарного лимфогистиоцитоза у детей. М.; 2015. 19 с. [Rumyantsev A.G., Maschan A.A., Maschan M.A. et al. Federal clinical guidelines for hemophagocytic lymphohistiocytosis diagnosis and management in children. M.; 2015. 19 p. (in Russian)]

2. Мазанкова Л.Н., Родионовская С.Р., Чебуркин А.А. и др. Гемофагоцитарный синдром в практике инфекциониста. Педиатрия. 2017; 96(4): 95-102. [Mazankova L.N., Rodionovskaya S.R., Cheburkin A.A. et al. Hemophagocytic syndrome in infectionists practice. Pediatria. 2017; 96 (4): 95-102. (in Russian)]. DOI: 10.24110/0031-403X-2017-96-4-95-102

3. Grangé S., Buchonnet G., Besnier E. et al. The use of ferritin to identify critically ill patients with secondary hemophagocytic lymphohistiocytosis. Crit. Care Med. 2016; 44(11): e1045-53. DOI: 10.1097/CCM.0000000000001878

4. McClain K.L., Eckstein 0. Clinical features and diagnosis of hemophagocytic lymphohistiocytosis. In: Post T.W., ed. UpToDate. Waltham, MA: UpToDate Inc.; 2017. URL: https://www.uptodate. com/home/linking-policy (дата обращения - 15.12.2020).

5. Lovisari F., Terzi V., Lippi M.G. et al. Hemophagocytic lymphohistiocytosis complicated by multiorgan failure. A case
Практически через месяц при отсутствии признаков дисфункции органов и нормализации показателей ребенок был выписан из стационара. В катамнезе (10 месяцев) у больной не отмечались гематологические отклонения.

В Армении молекулярно-генетическое исследование не проводится, но родителям даны рекомендации по проведению данного исследования за рубежом.

\section{ЗАКЛЮЧЕНИЕ}

При гемофагоцитарном лимфогистиоцитозе имеется высокий риск летального исхода, поэтому очень важны ранняя диагностика и своевременно начатая терапия. Особенность данного случая заключается в том, что нам удалось быстро поставить диагноз, рано начать лечение и получить полную ремиссию без агрессивной иммуносупресии.

report. Medicine (Baltimore). 2017; 96(50): e9198. D0I: 10.1097/ MD.0000000000009198

6. Schram A.M., Berliner N. How I treat hemophagocytic lymphohistiocytosis in the adult patient. Blood. 2015; 125(19): 2908-14. DOI: 10.1182/blood-2015-01-551622

7. Grom A.A. Primary hemophagocytic lymphohistiocytosis and macrophage activation syndrome: the importance of timely clinical differentiation. J. Pediatr. 2017; 189: 19-21.e1. D0I: 10.1016/j. jpeds.2017.07.025

8. Al Nasrallah N., Al-Hader A., Samala N. et al. Hemophagocytic lymphohistiocytosis in the medical ICU: a single-institution cohort study on acute liver failure and mortality. Crit. Care Explor. 2021; 3(1): e0318. D0I: 10.1097/CCE.0000000000000318

9. Morimoto A., Nakazawa Y., Ishii E. Hemophagocytic lymphohistiocytosis: patogenesis, diagnosis and management. Pediatr. Int. 2016; 58(9); 817-25. DOI: 10.1111/ped.13064

10. Score issued from the manuscript "Development and validation of a score for the diagnosis of reactive hemophagocytic syndrome (HScore)" by L. Fardet, L. Galicier, 0. Lambotte et al. Arthritis \& Rheumatology. 2014. URL: http://saintantoine.aphp.fr/score/ (дата обращения - 15.12.2020).

11. Henter J.I., Horne A., Arico M. et al. HLH-2004: Diagnostic and therapeutic guidelines for hemophagocytic lymphohistiocytosis. Pediatr. Blood Cancer. 2007; 48(2): 124-31. DOI: 10.1002/pbc.21039 D 